Article

\title{
Surface Subsidence in Urbanized Coastal Areas: PSI Methods Based on Sentinel-1 for Ho Chi Minh City
}

\author{
C. Elizabeth Duffy* ${ }^{*}$, Andreas Braun (1) and Volker Hochschild \\ Institute of Geography, University of Tübingen, 72074 Tübingen, Germany; an.braun@uni-tuebingen.de (A.B.); \\ volker.hochschild@uni-tuebingen.de (V.H.) \\ * Correspondence: carolyn.duffy@ggi.uni-tuebingen.de; Tel.: +49-7071-29-77572
}

Received: 15 October 2020; Accepted: 3 December 2020; Published: 17 December 2020

check for updates

\begin{abstract}
In Ho Chi Minh City (HCMC), Vietnam, though at present flooding is merely a recurring nuisance, there is increasing concern that a combination of impending climate change and rapid urbanization will significantly exacerbate the situation. Given the significant measures taken in HCMC to reduce groundwater extraction and sea-level rise (SLR) inundation since the most recent subsidence studies, we aim to update and contribute to the subsidence information of HCMC with continuous temporal coverage from 2017 to 2019. In this study, we use Persistent Scatterer Interferometry (PSI) with Copernicus Sentinel-1 data and open source tools to determine current subsidence rates within the urban center of HCMC. Additionally, the scalability of this method and use of freely accessible data allows for continuous updating and monitoring of this high-vulnerability region. The observed average subsidence rates were $3.3 \mathrm{~mm}$ per year with a maximum local subsidence of $5.3 \mathrm{~cm}$ per year. These results largely align with findings of previous studies and reflect similar spatial distributed subsidence patterns. Inundation risk awareness is enhanced by not only continued improved subsidence analysis, but also incorporating latest advancements in Digital Elevation Model (DEM) accuracy. This study compares local differences between traditionally used AW3D30 DEM with the CoastalDEM. Our findings indicate that although we identify lower than previously accepted elevations in the urban core, that stabilization of subsidence is observed in this same region.
\end{abstract}

Keywords: subsidence; Sentinel-1; persistent scatterer; interferometrics; PSI; Ho Chi Minh City; megacity; vertical displacement; APAC

\section{Introduction}

Coastal regions are popular settlement areas, most notably river deltas. Globally, over 500 million people live on deltas, of which many are increasingly exposed to the hazards that arise from rapid urbanization, climate change, and sea level rise [1,2]. Moreover, these deltas are considered hot spots of risks and vulnerabilities where social and environmental aspects are strongly coupled [3]. Coastal cities of Asia-Pacific (APAC) are home to the greatest number of people, over 151 million, who currently reside on land at risk of permanent inundation by 2100 [4]. For many of these cities, rapid urbanization and significant vulnerability to climate change has led to extensive undertakings by local governing bodies and institutions to address related and pressing issues such as subsidence. In urbanized deltas, land subsidence monitoring is an increasingly eminent component of risk-planning and decision-making regarding infrastructure [5,6]. This is particularly relevant for countries like Vietnam, where over 70 percent of the population live along the coasts and in the low lying deltas, which raises their exposition to natural hazards from both the inland and 
the sea side $[7,8]$. However, measuring subsidence requires a large scale monitoring framework, for example by a network of static differential global positioning system (dGPS) measurements [9] or extensive subsurface surveys (e.g., gravimeters or levelling data, [10]), which are expensive and require high maintenance frequencies. Other cities in APAC of similar population size to HCMC, such as Bangkok, have developed such extensive monitoring frameworks over recent decades and now yield viable results [11]. Yet, the construction and implementation of these networks take time and as it stands, no such network has been developed for HCMC. As an alternative, multi-temporal approaches of Synthetic Aperture Radar (SAR) Interferometry have been established, which measure surface deformations at millimetric accuracy based on satellite observations [12-14]. Especially Persistent Scatterer Interferometry (PSI) has proven effective in urban areas because of the stable phase information returning from man-made structures and artificial surfaces, such as buildings, roads or other coherent point targets [15,16]. It has been successfully applied in Vietnam, including Hanoi [17,18], Hué [19], Ben Tre province [20] and Ho Chi Minh City [21]. However, no studies exist which cover the latest dynamics of Ho Chi Minh City over the past five years and no previous study derives true vertical components of subsidence, and rather use LOS as a proxy. The latest InSAR studies published used data from 2010 or earlier [21,22].

\subsection{Study Area}

Ho Chi Minh City (HCMC) is located in the southern part of Vietnam, adjacent to the Mekong Delta at the mouth of the Dong Nai River Basin, and covers about $2094 \mathrm{~km}^{2}$ HCMC is Vietnam's largest city and officially home to over 8.5 million people according to recent records with 4292 people per square kilometer [23]. However, when rapid growth rates undocumented persons are factored in, population estimates approach 10 million inhabitants, making HCMC a megacity according to the UN-definition [24-26]. Moreover, trends of spatial diffusification in housing compound the issues related to population growth as the built-up area of HCMC increased by 48,418 hectares between 1999 and 2015 and the urban expansion rate; as well as a trend of suburbanization, is only increasing [27,28].

As depicted in Figure 1, HCMC is situated tangentially to one of the world's most sensitive areas to climate change, the Mekong Delta [29]. More than 50 percent of HCMC is situated lower than $1.5 \mathrm{~m}$ elevation above mean sea level [30], and as recent studies have proven, it is even lower than previously estimated with a mean elevation of only $1.32 \mathrm{~m}$ a.s.l. [4,31]. The HCMC region has a typical tropical wet and dry climate with an average temperature of $28^{\circ} \mathrm{C}$, which is incrementally increasing from climate change as well as the urban heat island effect, which accounts for a temperature differential of up to $10^{\circ} \mathrm{K}$ in urban areas as compared to rural [32]. As climate change causes more intense precipitation events [33] and urbanization results in an increase of impervious surface, the wet season of HCMC (May to October), which already provides about 85 percent of the total rainfall per year, is expected to increase local flood intensity [34].

Until recently, over $800,000 \mathrm{~m}^{3}$ of groundwater were extracted on a daily basis in HCMC which have significantly contributed to aquifer-system compaction and subsidence $[35,36]$. In recent years, rates of withdrawal have stabilized as a result of water acts passed in HCMC to restrict groundwater extraction $[37,38]$. Still, HCMC and the surrounding area is built on primarily deltaic alluvium with $200 \mathrm{~m}$ thick layers of soft clay [11,24]. Thus, compaction predominates with estimated rates of several centimeters per year in the nearby Mekong delta and subsidence is inevitable [39]. 


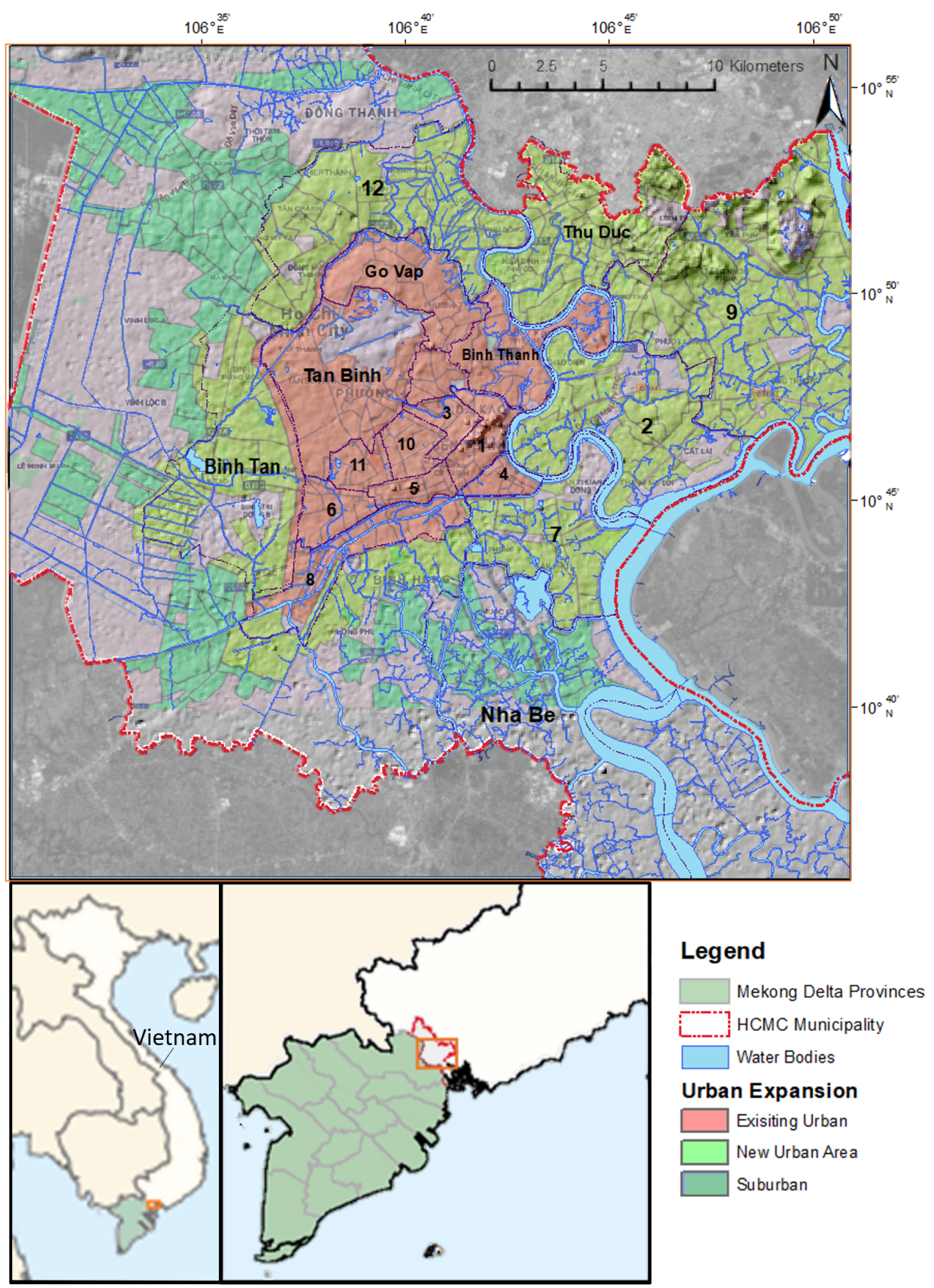

Figure 1. Study area of Ho Chi Minh City (HCMC) depicted as orange box in the lower right southern Vietnamese subset, masked by the municipal boundary of HCMC and with key districts of analysis and recent urban expansion where new urban zones are those with buildings erected primarily after 2008 while existing urban zones are comprised of buildings erected primarily before 2008, from the HCMC Dept. of Urban Planning and Architecture.

\subsection{Previous Studies and Research Objectives}

Generally in cities with suspected subsidence, networks of monitoring stations are implemented, which take time and investment and are yet to be well developed in HCMC. Multiple case studies of land subsidence have already been implemented over HCMC using remote sensing, and quantified through various interferometric techniques $[21,35,40]$ as well as a subsidence model based on hydrogeologic data [11]. However, these studies have not been updated recently, and have not yet included Sentinel-1 SAR observations nor the derivation of vertical motion from combining ascending 
and descending data. Regarding the interferometric studies, rates of $1-3 \mathrm{~cm} / \mathrm{yr}$ were observed in HCMC from January 2007 to November 2010 by Erban using ALOS data [35].

Recently published InSAR studies of HCMC and the surrounding area used data satellite data from 2010 or earlier [21,22], elucidating the need for more up-to-date subsidence rates. Additionally, these previous studies used ALOS data. ALOS revisit time was 35 days from it's launch in 2006 with an improvement of revisit time with ALOS-2 of 14 days beginning in 2014. However, the studies were conducted on time periods prior to this improvement, yielding a much lower maximum measurable differential deformation rate $(14.2 \mathrm{~cm} / \mathrm{yr}$ rather than the $46.8 \mathrm{~cm} / \mathrm{yr}$ achieved by ALOS-2 today).

All studies based on satellite interferometry have in common that they only investigate the displacement along the line-of-sight (LOS), which describes the change of the distance between the side-looking sensor and the earth's surface. As most radar satellites operate at incidence angles between 30 and 50 degrees, LOS displacements are a one-dimensional measure which does not directly represent the vertical elevation change linked to surface subsidence [41]. To avoid misinterpretations caused by movements in east-west direction and to prevent both overestimation and underestimation of subsidence, conversion to vertical displacement is required [42]. In this study, we tackle this outlined need for research and provide a more reliable and up to date estimation of surface subsidence in the HCMC metropolitan area using freely available data and the open source StaMPS approach, which can be readily updated for continuous monitoring. Significantly, this StaMPS method has the advantage that it does not require a prior deformation model, which is highly valuable for study replication in similar areas of Asia-Pacific [43]. Previous studies and techniques are leveraged to verify our findings and to allow us to differentiate which subsidence patterns have already been identified versus those which are new and may require further investigation. Finally, a dedicated analysis was performed highlighting vertical displacements along urban infrastructures and across land use types and municipal districts $[27,28]$.

The gathered information can be used to improve flood protection as well as for achieving a more efficient flood management as outlined by Lempert et al. [44]. HCMC is currently facing a very fast-paced urban growth. Due to this fact available geodata and land use information become outdated quickly. The HCMC Department of Planning and Architecture therefore depends on the latest land use data in order to direct the city's future development regarding a sustainable exploitation of groundwater resources [45] and risk-adapted urban development [30]. At this juncture, remote sensing provides the methods in order to generate high resolution and consistent land use data for a time series.

\section{Materials and Methods}

In this study, 121 Sentinel-1 images were acquired for the purpose of multi-temporal subsidence analysis. The Sentinel-1 constellation (A and B) are two ESA satellites acquiring images in C-band $(5.4 \mathrm{GHz})$ beginning in late 2014. Additionally, Sentinel-1 data are free and openly accessible via various sources and in our case, we used the Alaska Satellite Facility's open data portal due to the automated baseline assessment functionality [46]. The Sentinel-1 Terrain Observation with Progressive Scan (TOPS or TOPSAR) acquisition mode presents key advantages when compared to other sensors' modes, as it provides wide area coverage and short revisit period of only 6 or 12 days globally. Short temporal baselines increase the chance of coherent phase information between the primary and secondary images, thus contributing to a potentially higher density of Persistent Scatterers (PS) which can be exploited for the estimation of deformation along a time-series. As ascending data was only available at intervals of 12 days (Sentinel-1A, 61 products), descending data was also limited to S1A products (60 in total). The time series spanned from November 2017 to October 2019, as depicted in Table 1 . From the various available passes over our area of interest (AOI), we selected ascending track 128 (A128) and descending track 18 (D18). 
Table 1. Compilation of previous subsidence studies conducted over HCMC and their respective observations. Note that each aforementioned study leveraged LOS displacement.

\begin{tabular}{ccc}
\hline Previous Study & Data or Technique & Subsidence Rates \\
\hline Nguyen (2016) & - & Avg: $10 \mathrm{~mm} / \mathrm{yr}$ \\
Minh et al. (2015) & ALOS PSI from 2006 to 2010 & Avg: $10 \mathrm{~mm} / \mathrm{yr}$ \\
Erban et al. (2014) & ALOS InSAR from 2006 to 2010 & Max: $4 \mathrm{~cm} / \mathrm{yr}$ in HCMC \\
Trung \& Minh (2009) & ERS-1/2 PSI from 1996 to 2002 & Max: 11 mm/yr (No avg. displacement) \\
\hline
\end{tabular}

Persistent Scatterer Interferometry (PSI) techniques were used to assess the evolution of subsidence using the above radar data series. Persistent Scatterer Interferometry tracks changes over time by using phase history of scatterers with a strong amplitude, referred to as Persistence Scatterers (PS points, [16,43]). Characteristically, radar has high double-bounce backscatter off buildings, efficiently reflecting the signal back to the SAR sensor. Strong returns also come from metallic objects (bridges, silos, metal roofing, utility poles) due to high dielectric constants, and thus urban areas like the observed area of HCMC yield sufficient densities of PS points. Thus, the PSI technique exploits 'coherence islands' (e.g., buildings reflecting the radar signal emitted by the satellite) where the phases remain sufficiently stable over time. During the processing sequence, the different distortions (flat-earth phase, topographic phase, look angle error, atmospheric phase screen; [47]) contributing to the phase signal of each PS point are limited, leaving behind only the phase information related to the displacement along the line of sight (LOS).

All available images between November 2017 and October 2019 were used for this study Table 2. This period was selected for two reasons: Firstly, as previous studies have confirmed linear subsidence rates for the study area [21,22], so that the observation of a longer time span will not reveal further temporal dynamics (e.g., seasonal patterns related to groundwater discharge [11]). Secondly, it was a compromise between keeping phase noise and atmospheric impacts as small as possible (achieved by longer time-series [16]) and maintaining a minimum PS density of 50 points per square kilometer in the areas of interest, especially along roads and in the silty loam areas along the Sai Gon River, in the southwest of the city [21]). Furthermore, the primary images were selected from the middle of the time period, as depicted in Figure 2, in order to maintain the highest number of persistent scatterers.

Table 2. Sentinel-1 radar data observation time frame and dates of the selected primary images.

\begin{tabular}{cccc}
\hline Sentinel-1 Data & Start Date & End Date & Primary Date \\
\hline Ascending $(\times 62)$ & 3 November 2017 & 24 October 201 & 10 October 2018 \\
Descending $(\times 62)$ & 1 November 2017 & 22 October 2019 & 2 November 2018 \\
\hline
\end{tabular}

The snap2stamps package [48] was used in combination with the ESA Sentinel-1 Toolbox to prepare the radar data, as shown in Figure 3, starting with a pairwise TOPS co-registration for each secondary image with the primary date as shown in Table 1 for both data series (ascending and descending orbit). As shown in Figure 2a, perpendicular baselines largely ranged between 10 and $100 \mathrm{~m}$, thus granting for the reliable extraction of the vertical motion component [48]. The Enhanced Spectral Diversity (ESD, [49]) technique was applied to estimate the fine azimuth shift between the different bursts of the Sentinel-1 TOPS product. We used the Shuttle Radar Topography Mission (SRTM) 1 -arcsecond $(30 \mathrm{~m})$ digital elevation model for the co-registration and the later estimation and removal of the topographic phase though minimal in deltaic environments like that surrounding HCMC [50]. The stack of amplitude images and interferograms served as inputs for the actual PSI processing. 


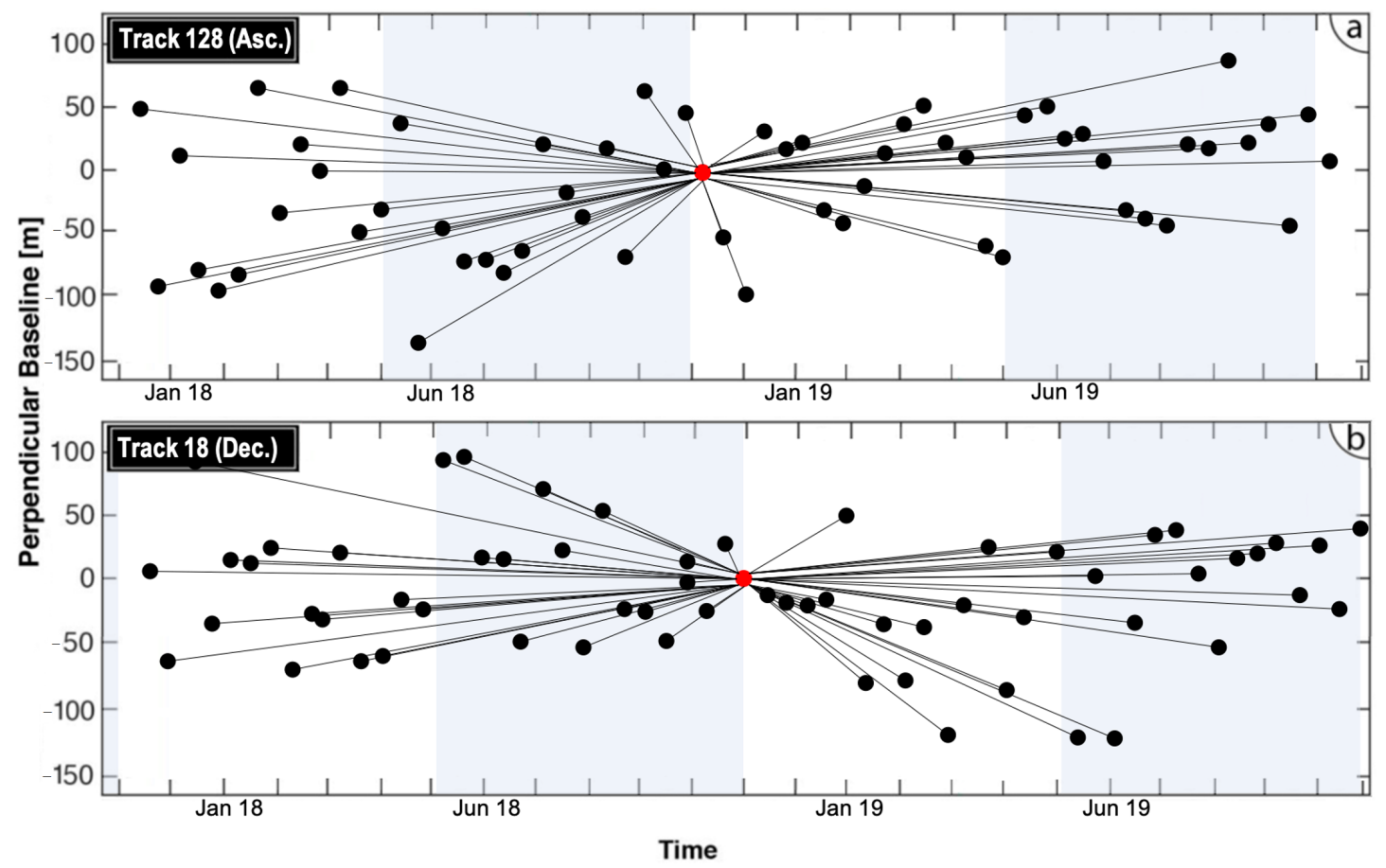

Figure 2. Baseline plots for both (a) ascending (A128) and (b) descending (D18) tracks. Perpendicular baselines are calculated with respect to the respective primary images highlighted in red.

The multi-temporal PSI analysis has been carried out using the open source StaMPS (Stanford Method for Persistent Scatterers) software packages [51], which implements a PSI method with a single primary baseline configuration, amplitude and phase information as pixel selection criteria, and spatial smoothness deformation model. Prior assumption of a deformation model is not required for the StaMPS method as alternatively, it obtains the real series differential phase by spatio-temporal 3D phase unwrapping [43]. Therefore, this method performs well even in areas. undergoing non-linear. deformation, uneven or localized subsidence and/or where the deformation characteristics are unknown, all of which are vital to examining the dynamic nature of HCMC as shown in previous studies [21]. The main steps of the StaMPS processing chain. are the selection and refinement of potential PS candidate pixels based on their temporal amplitude dispersion (mean backscatter divided by the standard deviation), the estimation of phase noise based on an iterative application of a Combined Low-pass and Adaptive Phase filter [43], filtering and removal. of noisy PS, and the estimation of the errors introduced by the spatially correlated and uncorrelated look angles using the above mentioned SRTM data. The phase information of the remaining coherent pixels is then unwrapped using the statistical-cost network-flow phase-unwrapping algorithm (snaphu) developed by Chen and Zebker [52] to convert them into absolute differences of LOS deformation. The processing is completed by a temporal low-pass filtering with a kernel size of 365 days to remove large outliers in the time-series of each pixel. This step reduces the impact of potential atmospheric effects in secondary images and smooths the phase signal in the temporal domain. It is not as effective as tools which actively correct atmospheric disturbances, such as TRAIN [53] or GACOS [54] and it is not suitable for non-linear deformation rate [51] but, as outlined above, these are not expected in the study area, and the technique is transparently applicable in any case.

The respective secondary images were prepared and split for automated processing, relative to their corresponding primary images. This process calls the TOPSAR Split and Apply Orbit operators, updating the annotated orbit information with more precise ones by applying the orbit files. Topo-phases were then removed for the TOPSAR data to then be co-registered, as depicted by Back Geocoding and Enhanced Spectral Diversity step of the Figure 3 below. Next, interferograms as "flat-earth" representations are produced and the contributions of the topographic phase removed. 
Lastly, the single primary DInSAR computations are made, resulting in a relative subsidence rate or a Line-of-Sight (LOS) subsidence rate.

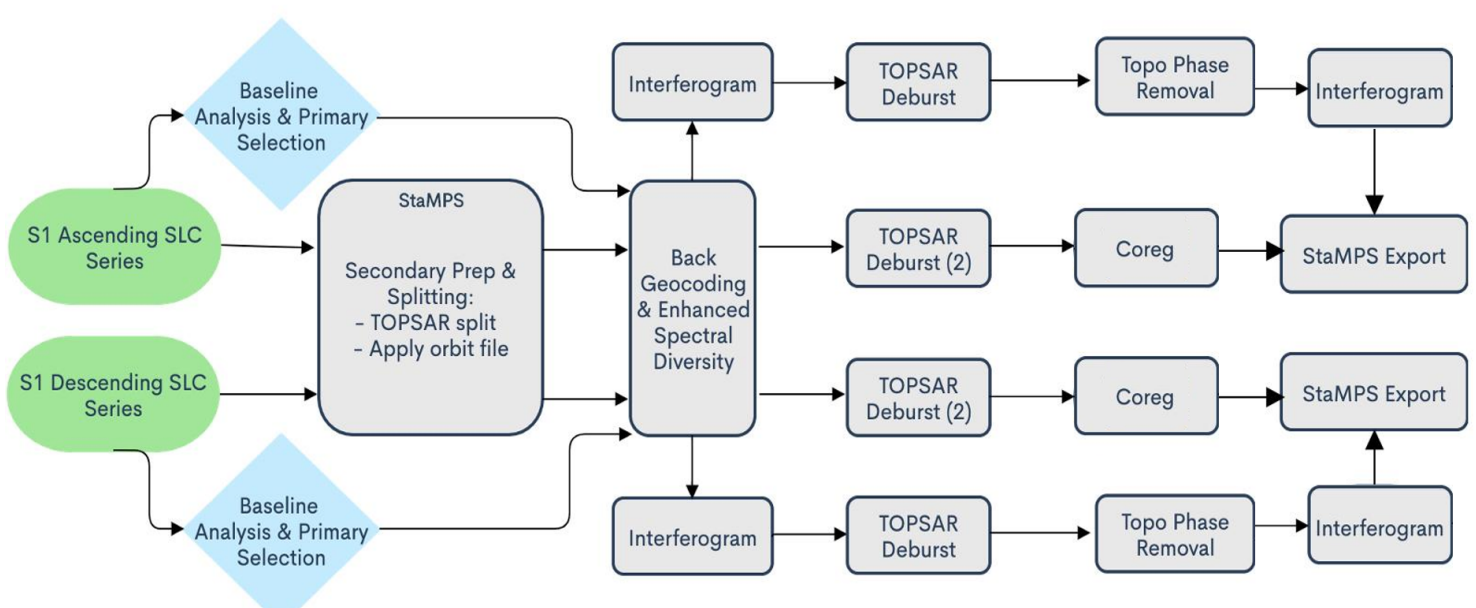

Figure 3. Schematic graph of all steps from preparation of interferometric inputs, to the StaMPS PSI processing, to finally the export before post-processing. The final StaMPS export yields LOS subsidence rates for both the ascending and descending series.

\section{Post-Processing}

We used the descending time series as a reference and converted it into a grid with a spatial resolution of $20 \mathrm{~m}$. All other data (ascending LOS displacement and both ascending and descending local incidence angles) were resampled to this grid accordingly. In a second step, pixels with both ascending and descending information were used in order to geometrically determine the vertical subsidence rates and horizontal displacement in descending azimuth look direction (hALD) rates from the coupled LOS rates, according to the following equations:

$$
\left[\begin{array}{l}
d_{\text {LOS }}{ }^{\text {sec }} \\
d_{\text {LOS }}
\end{array}\right]=A\left[\begin{array}{l}
d_{u p} \\
d_{h_{\text {ald }}}
\end{array}\right]
$$

with

$$
A=\left[\begin{array}{cc}
\cos \theta^{a s c} & \frac{\sin \theta^{a s c}}{\cos \Delta \alpha} \\
\cos \theta^{d e s c} & \sin \theta^{d e s c}
\end{array}\right]
$$

where $d_{\text {LOS }}$ is displacement along the Line-Of-Sight, $d_{u p}$ is the vertical displacement, $d_{h_{\text {ald }}}$ is the horizontal displacement, theta is the incident angle, and $\Delta_{\alpha}$ is the satellite heading difference between the ascending and descending orbits. As absolute distance to the sensor cannot be determined by differential interferometry, it is common practice to select a reference point or area where little to no subsidence is expected. In this study, we followed the suggestion of [21,55], and selected a part of district one as a highly stable region, to correct the vertical velocity to the sensor distance. Comparatively to this reference area, the majority of the study area is covered by loose, soft alluvial sediments [24]. After extracting and correcting the vertical component of the deformation velocities, we overlaid the vertical subsidence rates over physical and social characteristics of HCMC including Digital Elevation Models (DEMs), soil types, urban expansion data, and finally the districts of HCMC to assess the district level averages and distributions. We then compared these district-based deformation rates against district-level growth projections and visually interpreted land use plans [28,34]. 


\section{Results}

\subsection{LOS Deformation Rates}

We obtained the average PSI LOS deformation rates for both the ascending and the descending observation periods (Figure 4). Our AOI and the extent of Sentinel-1 ascending (A128) and descending (D18) orbits are illustrated in Figure 4 as well. A total of 570,182 pixels and 542,139 pixels were detected as PS points from the A128 track and D18 track, respectively. The comparable number of PS points as well as the standard deviation of the mean LOS velocities $(-0.49 \mathrm{~mm} / \mathrm{yr}$ for ascending and $-0.42 \mathrm{~mm} / \mathrm{yr}$ for descending), prior to any geometric corrections, serve as good indicators of compatibility between the two datasets.
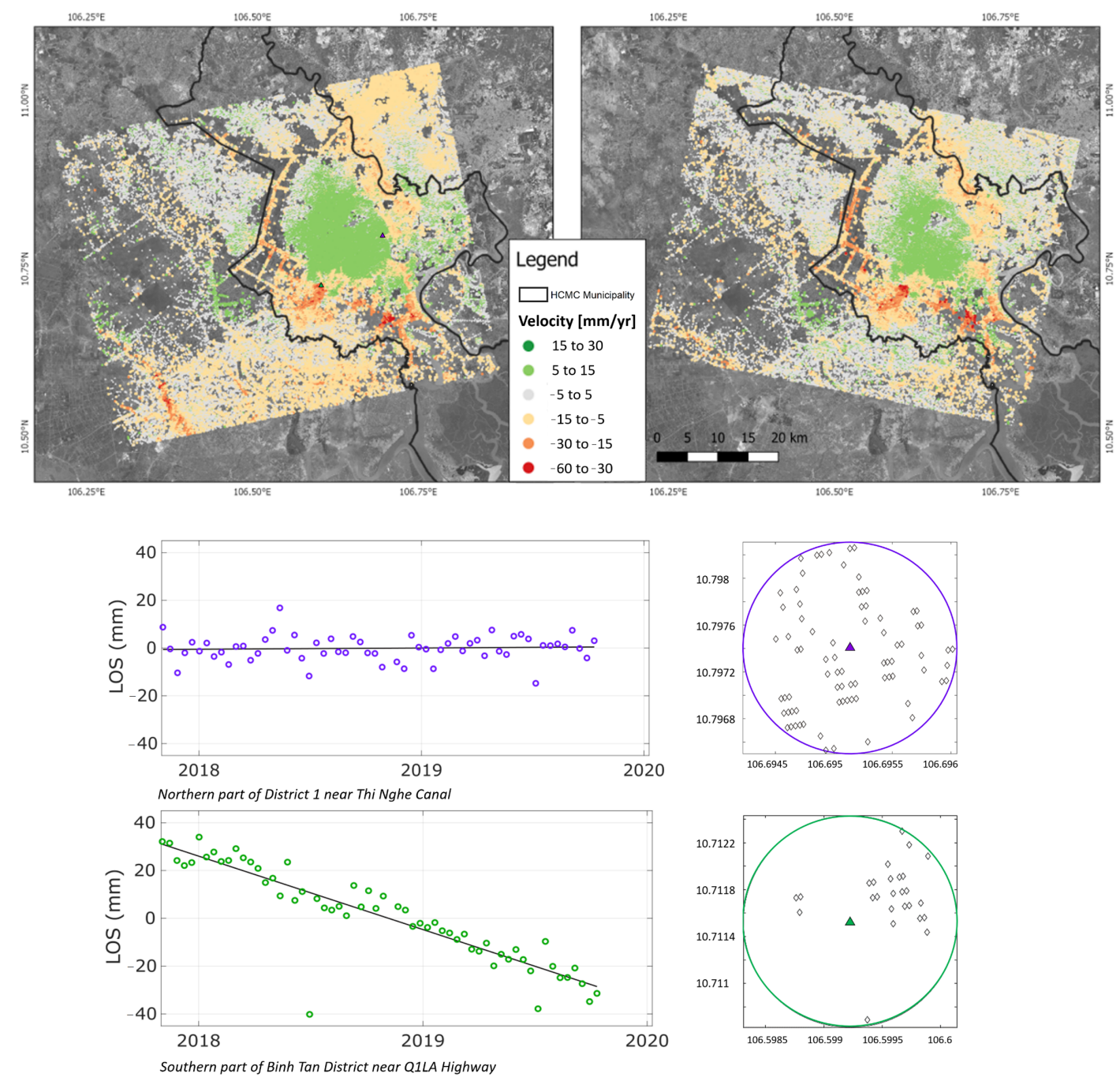

Figure 4. Average LOS displacement for for both ascending (left: track A128) and descending (right: track D18) tracks between 11/2017 and 10/2019 (top) and time-series plot for two selected sites (bottom).

In 2015, Minh et al. [21] estimated annual land subsidence rates of $8 \mathrm{~mm} / \mathrm{yr}$ and maximum rates of $70 \mathrm{~mm} / \mathrm{yr}$ using PSI methods using ALOS data from 2006 to 2010 and validated against leveling data with a RMSE of $4.3 \mathrm{~mm} / \mathrm{yr}$. The conversion between LOS subsidence to vertical subsidence was described as being obtained by "straightforward geometrical arguments." [21]). Erban et al. [22] used LOS directly without a conversion to vertical velocities. Conversely, our method 
leverages the ascending and descending tracks to generate vertical velocities, as described in Section 2, which yields relatively similar averages but increasingly divergent extremes, as depicted in Figure 5 below. We attribute this to the non-negligable influences of terrain and horizontal displacement on the phase interpretation and the potentially inaccurate estimation of the spatially correlated look angle error as described in the PSI processing.

Particularly with single-interferogram techniques, atmospheric signals can dominate when looking at small deformation signals over time whereas PSI techniques allow for the smoothing of interferograms through the time series and associated atmospheric noise contributions, allowing for improved vertical accuracies for slow deformations [16].

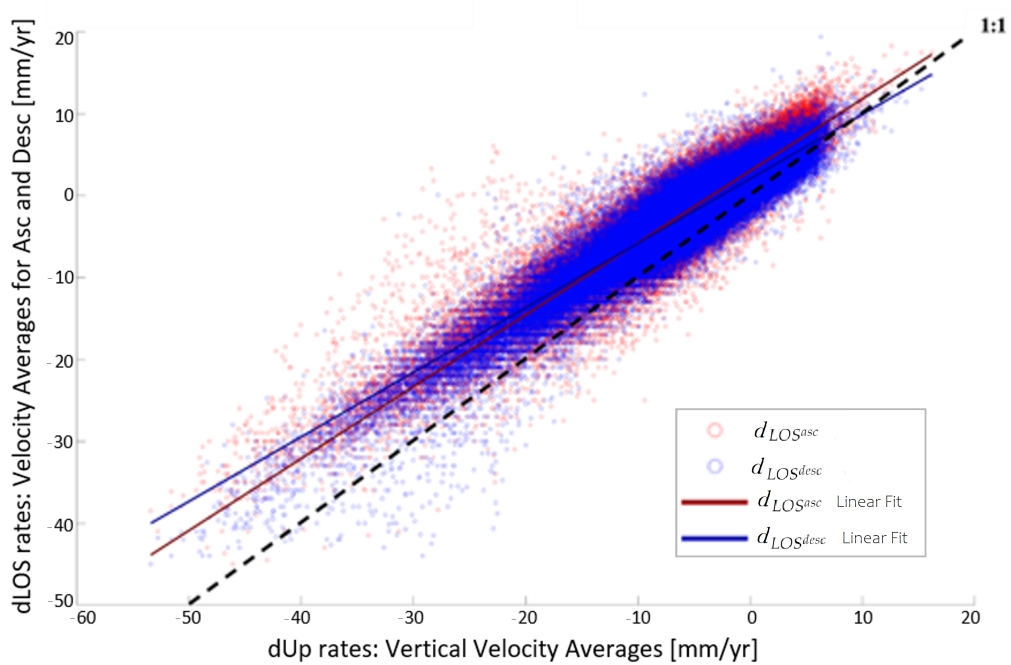

Figure 5. Scatterplot of LOS (asc and dec) subsidence and vertical subsidence. A one-to-one ratio is depicted as the black dashed line for relative measure, demonstrating the increasing influence of geometric correction with higher rates of subsidence.

\subsection{Vertical Deformation Rates}

Following the analysis of the LOS deformation rates, the vertical velocities were obtained as depicted in Figure 6. In eastern-central HCMC, the ground surface appears to be very stable, with few small subsiding spots identifiable near the Tan Son Nhat International Airport and along the Quoc lo 1A (QL1A) highway. For the surrounding areas, even positive velocities are observed. We attribute this phenomena to drastic changes in groundwater extraction policy and respective hydrogeologic responses. Just as previous groundwater extraction rates have been correlated with significant subsidence [22], conversely, decelerated subsidence can be observed with reduction of the groundwater extraction as a function of the changes of pore pressure and the nature of the aquifers [36]. Available hydrogeologic data did not permit more detailed consideration of these factors and thus it remains unclear to what degree if any can this phenomena be attributed to error. The time-series plots in the bottom of the figure show the LOS deformation rates of all PS within a radius of $100 \mathrm{~m}$ over the investigated period. They confirm the static nature of large parts of the center of HCMC, but also prove that the observed subsidence in areas of larger deformation is of linear nature and that the stability of the phase information is sufficient to retrieve reliable and accurate average subsidence rates. 


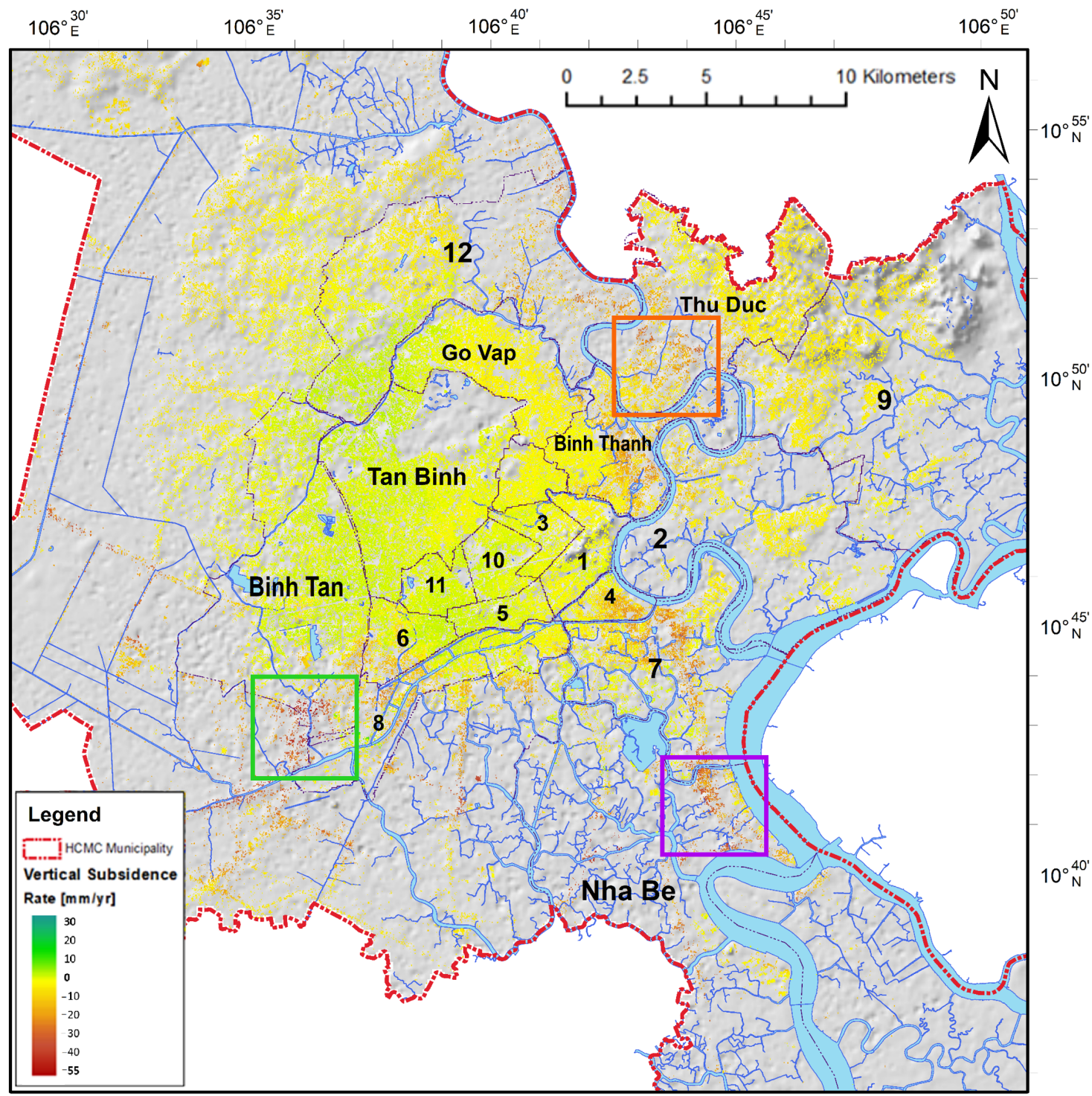

Figure 6. Average vertical subsidence rates for the period of January 2016 to June 2019. A hillshade of the $90 \mathrm{~m}$ res CoastalDEM is the background and an orthophoto for spatial context around HCMC. Colored boxes delineate the locations for reference in later figures.

Comparison of the vertical subsidence against the best Digital Elevation Models (DEMs) available is contextually vital considering HCMC's low-lying topography. Previously, experts used the SRTM or more recently, the ALOS DEM (ALOS W3D30, [56]) as the best source of truth to juxtapose against subsidence and potential inundation information [21,22]. However, as Kulp and Strauss [4] indicate, positive vertical bias of the SRTM models and the AW3D30 Model from ALOS does not specifically attempt to improve vertical bias in urban or densely vegetated areas, as is necessary for HCMC's relatively flat, low-lying, highly urbanized setting. Thus, the Coastal-DEM was developed specifically for this purpose of reducing vertical bias in coastal cities with elevations close to sea level, while remaining freely available or low-cost. As depicted in Figure 7, the vast majority of HCMC lies below $5 \mathrm{~m}$ elevation, so even small differences in vertical RMSEs can have significant impact on flood vulnerability and subsidence analysis. Notably, the AW3D30 DEM presents a vertical Root Mean Square Errors (RMSE) of $5.68 \mathrm{~m}$ while the CoastalDEM has an RMSE of 1.54 [57,58]. The most significant subsidence rates are observed in the rapidly urbanizing areas in peripheral districts as well as in areas of low elevation. 


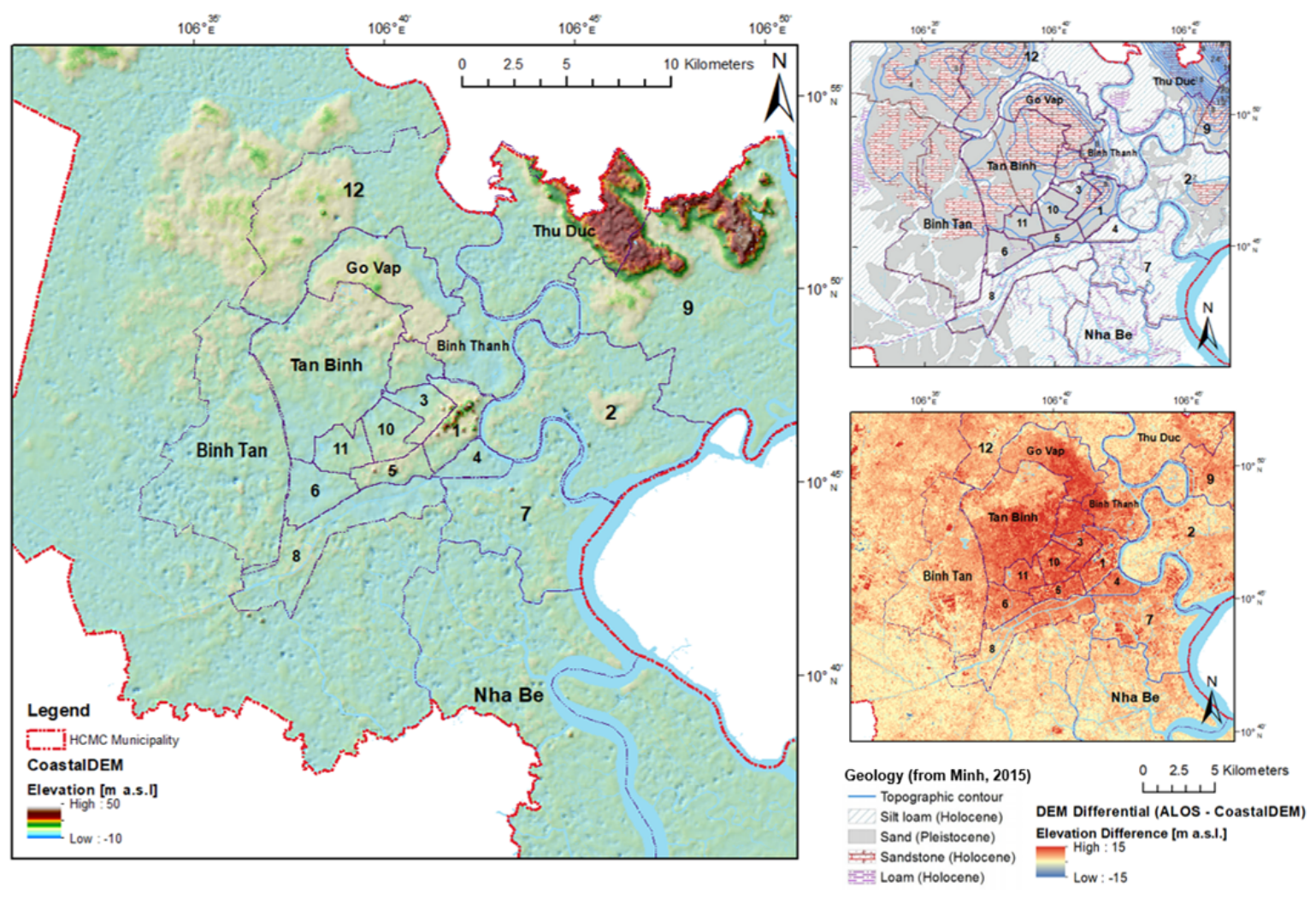

Figure 7. Coastal-Digital Elevation Model (DEM) of HCMC (left), the geology and topographic contour of ALOS data used in Minh 2015 (top right) and the elevation difference between the ALOS DEM and Coastal-DEM (bottom right).

The final number of PS points was 314,942 or $40.2 \mathrm{pts} / \mathrm{km}^{2}$, with the majority of these scatterers corresponding to buildings and infrastructures located in the dense urban framework of inner HCMC but also the surrounding peri-urban districts, which can be attributed to the stable nature of anthropogenic structures resulting in high coherence between SAR acquisitions. Places lacking PS points correspond to water bodies, areas under construction during the observation period, and agricultural or vegetated areas. Beyond the highly clustered spatial distribution patterns of the observed PS points, various deformation velocity patterns are easily identifiable, with the most severe velocities adjacent to water bodies and a NW-SE trending axis. We observed a mean annual vertical displacement velocity of $3.3 \mathrm{~mm} / \mathrm{yr}$ for the observation period of 2017 to 2019 over a highly heterogeneous velocity field.

\subsection{Key Districts and Infrastructure}

Subsidence rates were analysed on the district level, yielding box plots of key districts as shown in Figure 8. Local maximums are even higher than expected with a maximum local subsidence of around $5 \mathrm{~cm} / \mathrm{yr}$ or more in certain areas of the Nha Be, Thu Doc, and Binh Tan districts, which are urban sprawl areas. In comparison, a previous study conducted by Erban et al. [22], which was in good agreement with hydrogeologically based methods, indicated a maximum of $4 \mathrm{~cm}$ subsidence, though local scales remain obscured in the aforementioned study. For urban planners, local maximums are even more significant to know where to act. However, although the comparison of districts shows a clear distinction between stable and dynamic areas, the maximum values have to be interpreted with respective care because outliers can also be produced during the phase unwrapping, especially in areas with a low PS density. Still, the interquartile ranges (IQRs) confirm the dominance of strong subsidence in some districts (Figure 8). 


\begin{tabular}{|c|c|c|c|c|c|c|c|c|c|c|c|c|c|c|c|c|}
\hline District & Nha Be & 1 & 2 & 3 & 4 & 5 & 6 & 7 & 8 & 9 & 10 & 11 & 12 & Binh Tan & Binh Thanh & Thu Doc \\
\hline & 15 & 211 & 42 & 264 & 188 & 266 & 248 & 85 & 126 & 36 & 241 & 273 & 99 & 236 & 144 & 111 \\
\hline
\end{tabular}

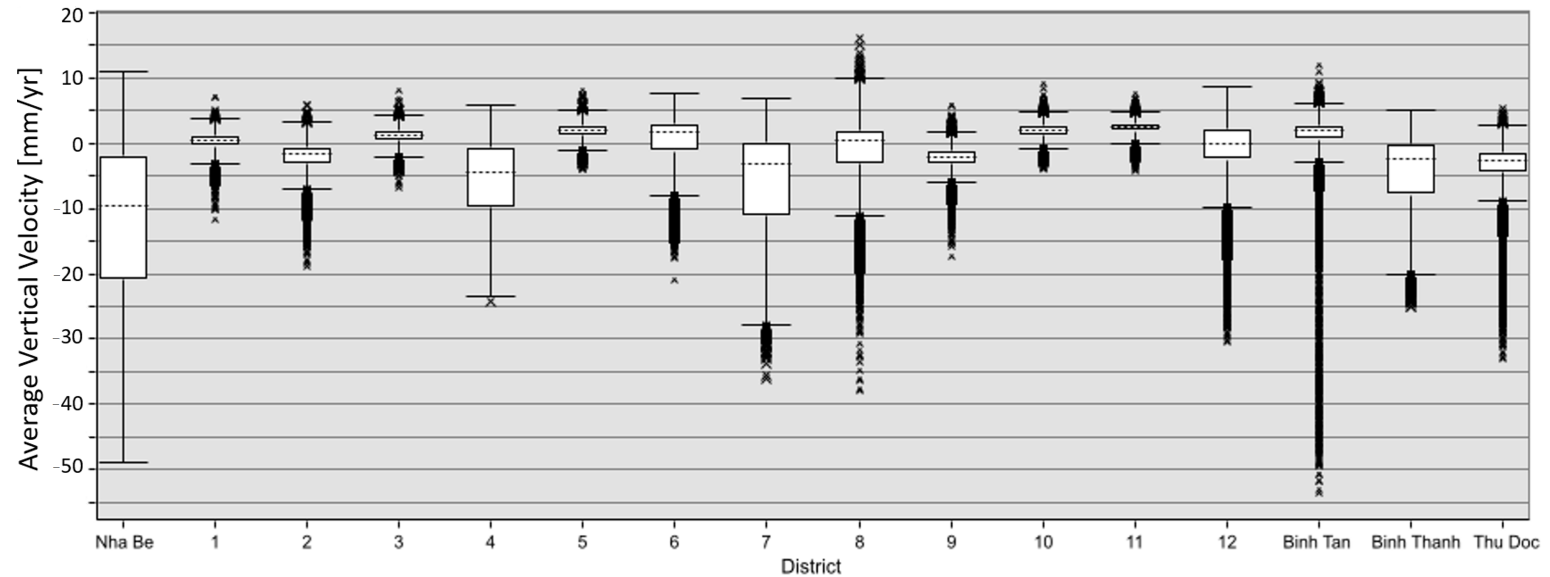

Figure 8. Box and Whisker plots of key HCMC Districts and outliers based on a standard 1.5*IQR whisker representation, with points per sq $\mathrm{km}$ for each key district identified in the embedded table above. Points per sq $\mathrm{km}$ elucidate the variance in the spread of the boxes, whiskers, and outliers in this plot.

Areas where the most significant subsidence rates were observed coincide with areas that were both recently urbanized or a part of suburban sprawl, while the historically urbanized center remains relatively stable [28]. The spatial velocity profiles of Figure 9a,b overlay areas of suburban sprawl while the area of Figure $9 \mathrm{c}$ overlays recently urbanized areas. Additionally, the extreme subsidence PS points in Binh Tan, Nha Be, and Thu Doc were located over silty loam deposits, the two soil types identified in previous studies to show the highest subsidence rates in HCMC [11,21].
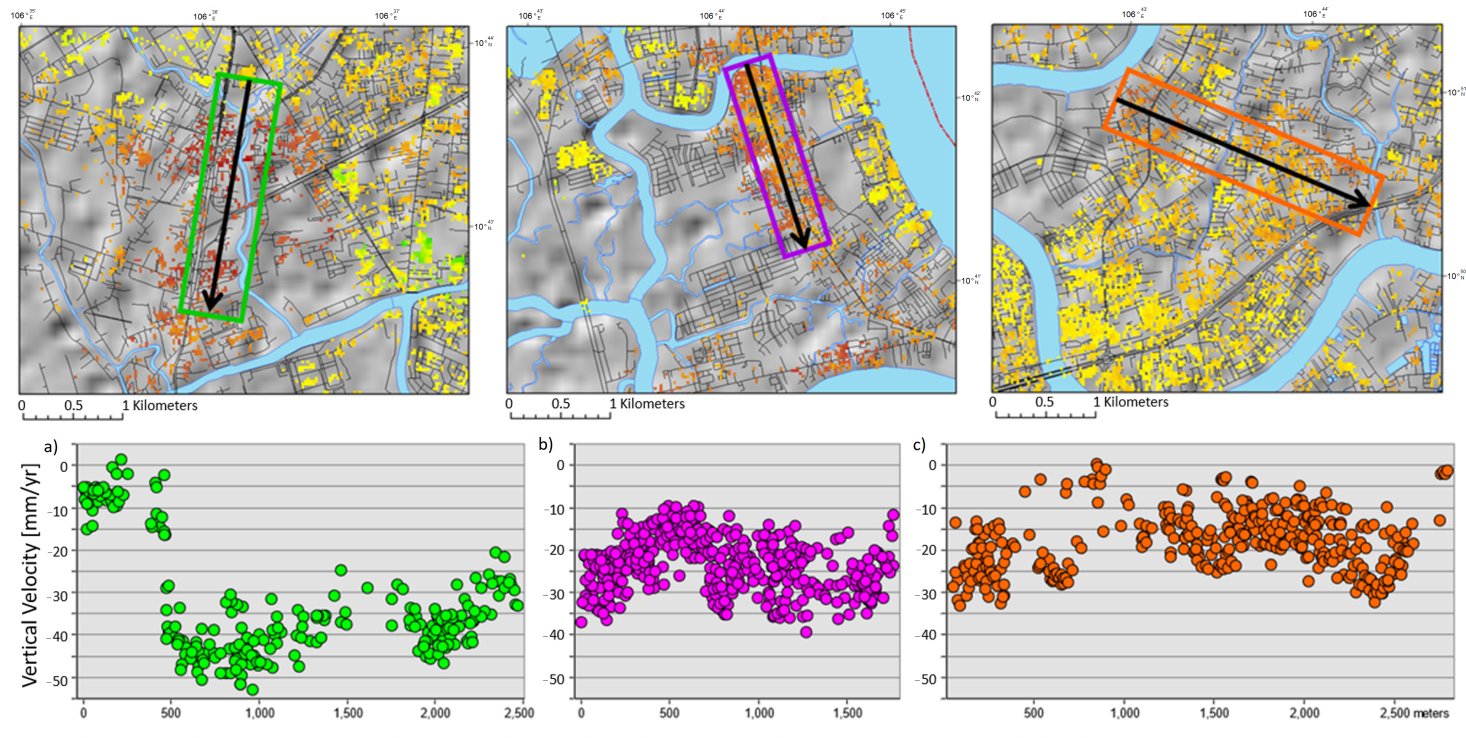

Binh Tan district, along QL1A highway \& kenh Tham Luong river

Nha Be district, along Huynh Tan Phat

Thu Doc district, along Duon Hiep Bin

Figure 9. $(\mathbf{a}-\mathbf{c})$.Close-up subsidence rate maps and vertical velocity profiles of (a) a semi-industrial area of Binh Tan, (b) a relatively new residential area of Nha Be, and (c) existing urban area of Binh Thanh. The basemap is the CoastalDEM (90 m res) with OpenStreetMap local roads overlain. Colors of boxes correspond with spatial locations of bounding boxes found in Figure 6. 
These vertical velocity profiles show a high degree of clustering or lack of noise in the data. The velocity profile of Figure 9a traverses across the Tham Luong canal, where north of the river subsidence is moderate at approximately $-8 \mathrm{~mm} / \mathrm{yr}$ and across the river bank, the highest subsidence velocities are observed of up to $-55 \mathrm{~mm} / \mathrm{yr}$. Considering the spatial smoothing inherent in the StaMPS method as well as the lack of noise, this stark transition is consequential. In contrast, Figure 9c is situated in an area of greater urban density and presents patches of relatively more noise in the data, with the majority of the noise occurring near the transect of a highway, Quoc lo 13. The zone encompassed by Figure $9 \mathrm{~b}$ is situated at the lowest elevation of the three velocity profiles and follows along a main road in a more recently developed suburban area.

\section{Discussion}

\subsection{Findings and Outlook}

In this work, a comparative analysis of LOS displacement and derived vertical displacement was carried out in order to determine the significance of vertical correction, and it was found that the value of the correction increases with higher observed subsidence. Although both subsidence and uplift features are observed in this study, subsidence features predominate. The majority of relatively rapid subsidence occurs in the southern portion of HCMC. Other natural patterns emerge in the results such as higher velocities are coincident with low lying topographies adjacent to major rivers or canals and zones with predominantly fine unconsolidated sediments near the surface. Each of the three zones depicted in Figure 9a-c were low-lying and adjacent to water bodies, which may indicate erosional forces from inundation as the predominant influence of local subsidence extremes. Additionally, a thick aquitard of soft clay lies beneath the areas of Figure 9a-c as well as majority of the subsiding region $[11,21]$. Such units have been shown to continue to compact due to their high compressibility, low permeability, and significant creep behavior, even long after groundwater withdrawal has been reduced [59]. Conversely, the urban core and other north east districts, where stability and even uplift is observed, are situated on top of predominantly sandstone aquifers [11,21]. Yet, surface uplift is dependent on a variety of factors such as deformation characteristics of soils, history of groundwater level fluctuation, and the thickness and permeability of units [59].

Despite many potential naturally occurring influences on local subsidence and uplift dynamics, anthropogenic factors may persist as higher velocities are also observed occurring on recently urbanized or built-up areas, while uplift and stability is observed in the majority of the existing urban center where groundwater depression cones in the second, third, and fourth aquifers had previously been identified [11]. In contrast, both profile 9a in the more industrial district of Binh Tanh and with profile $9 \mathrm{~b}$ coincide with areas where previously some of the greatest drawdown was observed. The study by Thoang and Giao leveraged groundwater drawdown data from 1999 to 2009. The disparity between the historical groundwater contours of these aquifers with observed subsidence may reflect aforementioned groundwater policy shifts, subsequent shifts in extraction and Groundwater Piezometric Head (GPH), and resulting pore-pressure induced subsidence and uplift. In studies of similar urban deltas of APAC with recent groundwater policy changes, periods of rebounding have been observed despite histories of extreme groundwater extraction, predominant unconsolidated soils, and large loads from extensive urban areas [59,60]. The presence of some observed uplift may suggest that aquifer-system deformation resulting from groundwater withdrawals in HCMC has remained in the elastic (recoverable) range of stress at least in the urban core and north east districts. However, it is not possible to determine conclusively whether the subsidence is recoverable (elastic or permanent) or to what degree the observed uplift and increased stability in the urban core of HCMC is attributable to changing hydrogeological conditions. Uplift in particular only occurs with the expansion of all rebounding units exceeds the compaction of all compressing units. Potential links between the subsidence and uplift behaviors found in this study and hydrogeological dynamics should be further investigated to reflect recent changes in 
updated GPH, groundwater extraction data, and drawdown and compared against other potential influences. Furthermore, generally the recoverable deformation is a relatively small portion of the total deformation, especially when the groundwater levels drop beneath their historically lowest values.

\subsection{Implications and Limitations}

Regarding the interpretation of the PSI results, a few advantages and limitations should be noted. First, the subsidence monitoring capabilities achievable with geodetic survey techniques are markedly different from that of remote sensing techniques in scale, required resources, and accuracy. The former requires significant analysis time and financial investment and it is inherently limited spatial scale, though generally superior in accuracy and with strategically located points. In contrast, remote sensing methods have rapid execution times and minimal pay-ins, with the methods used in our study using free and systemically available Sentinel-1 data and yielding a robust solution that needs only a short observation period. However, the opportunistic sampling of PSI techniques based on the consistency of backscatter over time, yields results that should be carefully assessed against the land use. Further investigation of observed subsidence rates against the temporal evolution of land cover is required in order to characterize the evolution of subsidence in relation to HCMC's dynamic urban environment.

As shown in Figure 4, the retrieved information on displacement is not only linear over time, but also the technique provides sufficient accuracy to derive the average subsidence in the study area with high precision Figure 4. Looking at single interferograms, smaller inaccuracies are introduced by phase noise and atmospheric disturbance up to a level of $+/-10 \mathrm{~mm}$ per year, but these play no role in as they form a clear and stable trend over the entire investigated perio. Although this study was able to confirm the deformation hot spots of previous studies and to give more up-to-date numbers on vertical subsidence, the lack of reliable and independently collected validation data is a clear shortcoming. However, we convey the confidence in the results of our study, comparing our study against reference points from previous studies, in the supplementary figures which can be found in our supplementary materials. The stability of the temporal results Figure 6 and the low subsidence rates in large parts of the city give little reason to mistrust the results, however an accuracy assessment would make the outcomes more valuable by knowing the amount of error to be expected in the data. Accordingly, the results could be compared to field measurements of subsidence rates at selected points (e.g., by dGPS surveys). As an alternative, an independent validation and plausibility check can be conducted by straightforward field campaigns in selected areas of high predicted subsidence, as proposed by Dang [61] who identified and documented cracks in buildings and foundations based on their PSI findings in Hanoi.

Second, the gradients of the phase changes, including along the profile lines in Figure $9 \mathrm{a}-\mathrm{c}$, may have artefacts from the unwrapping of the phase information. In traditional interferograms, phase information is integrated into a continuous surface, generally a 2-D surface pixel-wise interpolation using spatial neighbors while PSI unwrapping is conducted in the temporal domain based on the phase difference of nearby PS pixels [51]. In order to properly unwrap the phase in PSI techniques, the phase difference between two adjacent points, either in time or space, are assumed to be within half a cycle. If this assumption is violated, the unwrapping of the phase could induce an unreasonably large trend or measure no motion when in reality, there is a large trend. Therefore some of these estimates could be unrealistic, despite otherwise correct scatterers. However, even in this case the overall pattern should be relatively consistent. The best way to assess this is with leveling data over the period of study or at least comparing a histogram of results against histograms of previous studies, both of which are not available. Yet, visual interpretation of results from previous studies [11,21] indicate similar patterns of extreme subsidence in both the Binh Tan and Thu Doc districts, but to a lesser extent in Nha Be which has seen rapid suburban sprawl over the past decade.

Finally, PSI techniques are limited in their capability to measure "fast" deformation phenomena due to the ambiguous nature of interferometric observations, i.e., the wrapped phase information, 
in that if the differential deformation phase between two subsequent acquisitions is larger than a given function of the wavelength and revisit interval, there is no reasonable means of retrieving true deformation rates [16]. Therefore, the short revisit of Sentinel- 1 of 12 days offers an advantage that ensures deformations up to $1.4 \mathrm{~cm}$ between acquisitions that can be adequately measured. Furthermore, to make the results more reliable and usable for urban planning, future studies should aim at minimizing phase noise by the integration of atmospheric corrections as suggested by Bekaert et al. [53]. Yet, the large correspondence of the results with those of other studies and the little degree of noise in the time-series plots indicate that the impact of these errors is already within a tolerable range.

In future research, additional emphasis should be placed on the reasons or triggers for subsidence in the metropolitan area of HCMC. As outlined in the beginning, there are various reasons for such processes in Vietnamese coastal cities, such as groundwater extraction [22], urbanization [21], poor drainage and insufficient management [62], and geological or geomorphological preconditions [19]. Only if these interrelations are well understood, and combined with runoff simulations such as presented by Dang et al. (2017) [63], urban planning can develop locally adjusted and effective measures for mitigation. In addition, future research should explore the elasticity of the soft clays that dominate the south east regions of HCMC, where subsidence is the most extreme, as subsidence in these areas may be less likely rebound from anthropogenic activity $[59,60]$. Furthermore, this region coincides with newly urbanizing zones and expanding residential areas which has several implications including increasing populations at risk as well as increasing consolidation under added loads.

Assuming an above average SLR of 0.2-0.4 cm/yr [64], continued rates of observed subsidence into 2050, one could conservatively estimate about $15.9-16.5 \mathrm{~cm}$ of potential inundation increase on average in HCMC, with extremes up to $1.65-1.71 \mathrm{~m}$. However, with substantial measures undertaken by the local government to reduce groundwater extraction and implement strategic urban planning, a continued decrease in subsidence may be observed as storage is restored [36]. As subsidence in HCMC and the broader Mekong Delta has been primarily attributed to compaction from aquifer depletion in previous studies [22], the effects of changes in both groundwater extraction and infiltration are not negligible. Future works should therefore take a multi-temporal approach between localized subsidence, groundwater levels, and land cover evolution.

\section{Conclusions}

This study showed how openly available Sentinel-1 data can be used to retrieve precise and up to date vertical displacements for the metropolitan area of HCMC. Our research aimed to update and improve subsidence rate estimations in HCMC by assessing a more recent time frame as well as generating a direct representation of vertical subsidence motion, rather than using the more traditional line-of-sight (LOS) displacement measure. The presented research involved assessing and mapping the subsidence rates in central districts of Ho Chi Minh City (HCMC, Vietnam) by analyzing both ascending and descending images from the SENTINEL-1 satellites with Persistent Scatterer Interferometry (PSI) methods from a single temporal interval (2017-2019). Two successive approaches, i.e., LOS displacement with PSI techniques and derived vertical displacement were applied and compared. Our analysis suggests that much of the main urban center of HCMC has a comparably stable average subsidence rate compared to studies conducted over previous decades [11,21], reflecting recent changes in groundwater extraction policies. In the urban core and north east districts, observed uplift may suggest that aquifer-system deformation resulting from groundwater withdrawals in HCMC has remained in the elastic (recoverable) range of stress, but further investigation is needed. However, results also indicate that rapidly urbanizing areas in peripheral districts as well as the road networks are experiencing continued intense subsidence of up to $5.3 \mathrm{~cm} / \mathrm{yr}$, notably in Binh Tan, Thu Doc, and Nha Be. Likely influences include continued groundwater extraction, lag effects from previous groundwater withdrawals, urbanization, poor drainage and 
erosional forces, and geological or geomorphological conditions. We indicate the need for similar localized analysis in dynamic, rapidly urbanizing coastal areas subject to heterogeneous deformation and give details on the application of StaMPS PSI processing with freely available Sentinel-1 data for continuous assessment.

Supplementary Materials: The following are available online at http:/ /www.mdpi.com/2072-4292/12/24/4130/s1, Figure S1: Vertical velocities of reference points for validation proxy, Figure S2: Spatial distribution of reference points, Figure S3: Temporal analysis in District 8-an area of rapid subsidence, Figure S4: Interferograms of unwrapped phases.

Author Contributions: Conceptualization, C.E.D., A.B. and V.H.; methodology, C.E.D. and A.B.; software, C.E.D. and A.B.; validation, C.E.D.; data analysis, C.E.D. and A.B.; writing-original draft preparation, C.E.D.; writing-review and editing, C.E.D., A.B. and V.H.; visualization, C.E.D.; supervision, project administration and funding acquisition, V.H. All authors have read and agreed to the published version of the manuscript.

Funding: We acknowledge the funding of the current DECIDER study by the German Ministry for Education and Research (BMBF) under the support code 01LZ1703F.

Acknowledgments: We acknowledge the many Vietnamese partners of the DECIDER project and their ongoing support to DECIDER objectives. LaAll Sentinel-1 data were provided by the European Space Agency (ESA) within the Copernicus Programme. ALOS W3D30 data were provided by JAXA. We support the statement of UNAVCO/WINSAR regarding the terminology of primary and secondary images in radar interferometry (https: / comet.nerc.ac.uk/about-comet/insar-terminology/) and used these terms in this article accordingly.

Conflicts of Interest: The authors declare no conflict of interest. The funders had no role in the design of the study; in the collection, analyses, or interpretation of data; in the writing of the manuscript, or in the decision to publish the results.

\section{Abbreviations}

The following abbreviations are used in this manuscript:

$\begin{array}{ll}\text { ALOS } & \text { Advanced Land Observing Satellite } \\ \text { AOI } & \text { Area of Interest } \\ \text { APAC } & \text { Asia-Pacific } \\ \text { ASF } & \text { Alaska Satellite Facility } \\ \text { DEM } & \text { Digital Elevation Model } \\ \text { dGPS } & \text { differential Global Positioning System } \\ \text { dhald } & \text { horizontal displacement } \\ \text { dLOS } & \text { displacement along Line-of-sight } \\ \text { dup } & \text { vertical displacement } \\ \text { ESA } & \text { European Space Agency } \\ \text { GPH } & \text { Groundwater Piezometric Head } \\ \text { HCMC } & \text { Ho Chi Minh City } \\ \text { InSAR } & \text { Interferometric Synthetic Aperture Radar } \\ \text { IQR } & \text { Interquartile Range } \\ \text { LOS } & \text { Line-of-Site } \\ \text { MoNRE } & \text { Ministry of Natural Resources and Environment in Vietnam } \\ \text { PSI } & \text { Persistent Scatterer Interferometry } \\ \text { RMSE } & \text { Root Mean Square Error } \\ \text { SAR } & \text { Synthetic Aperture Radar } \\ \text { SLC } & \text { Single Look Complex } \\ \text { SLR } & \text { Sea-Level Rise } \\ \text { SRTM } & \text { Shuttle Radar Topography Mission } \\ \text { StaMPS } & \text { Stanford Method for Persistent Scatterers } \\ \text { TOPSAR } & \text { Terrain Observation with Progressive Scans SAR } \\ & \end{array}$

\section{References}

1. Giosan, L.; Syvitski, J.; Constantinescu, S.; Day, J. Climate change: Protect the world's deltas. Nature 2014, 516, 31-33. [CrossRef] 
2. Tessler, Z.D.; Vorosmarty, C.J.; Grossberg, M.; Gladkova, I.; Aizenman, H.; Syvitski, J.P.M.; Foufoula-Georgiou, E. Profiling risk and sustainability in coastal deltas of the world. Science 2015, 349, 638-643. [CrossRef] [PubMed]

3. Hagenlocher, M.; Renaud, F.G.; Haas, S.; Sebesvari, Z. Vulnerability and risk of deltaic social-ecological systems exposed to multiple hazards. Sci. Total. Environ. 2018, 631-632, 71-80. [CrossRef] [PubMed]

4. Kulp, S.A.; Strauss, B.H. New elevation data triple estimates of global vulnerability to sea-level rise and coastal flooding. Nat. Commun. 2019, 10, 4844. [CrossRef] [PubMed]

5. Erkens, G.; Bucx, T.; Dam, R.; de Lange, G.; Lambert, J. Sinking coastal cities. Proc. Int. Assoc. Hydrol. Sci. 2015, 372, 189-198. [CrossRef]

6. Saxena, N.C. Subsidence Management Handbook; Scientific Publishers: Jodhpur, India, 2003.

7. Bangalore, M.; Smith, A.; Veldkamp, T. Exposure to Floods, Climate Change, and Poverty in Vietnam; Policy Research Working Paper WPS7765; World Bank Group: Washington, DC, USA, 2016.

8. Duy, P.N.; Chapman, L.; Tight, M.; Thuong, L.V.; Linh, P.N. Urban Resilience to Floods in Coastal Cities: Challenges and Opportunities for Ho Chi Minh City and Other Emerging Cities in Southeast Asia. J. Urban Plan. Dev. 2018, 144, 05017018. [CrossRef]

9. Santos, S.M.; Cabral, J.J.S.P.; Pontes Filho, I.D.S Monitoring of soil subsidence in urban and coastal areas due to groundwater overexploitation using GPS. Nat. Hazards 2012, 64, 421-439. [CrossRef]

10. Kersten, T.; Kobe, M.; Gabriel, G.; Timmen, L.; Schön, S.; Vogel, D. Geodetic monitoring of subrosion-induced subsidence processes in urban areas. J. Appl. Geod. 2017, 11. [CrossRef]

11. Thoang, T.; Giao, P. Subsurface characterization and prediction of land subsidence for HCM City, Vietnam. Eng. Geol. 2015, 199, 107-124. [CrossRef]

12. Crosetto, M.; Castillo, M.; Arbiol, R. Urban Subsidence Monitoring Using Radar Interferometry. Photogramm. Eng. Remote Sens. 2003, 69, 775-783. [CrossRef]

13. Ferretti, A.; Colombo, D.; Fumagalli, A.; Novali, F.; Rucci, A. InSAR data for monitoring land subsidence: Time to think big. Proc. Int. Assoc. Hydrol. Sci. 2015, 372, 331-334. [CrossRef]

14. Bianchini, S.; Solari, L.; Del Soldato, M.; Raspini, F.; Montalti, R.; Ciampalini, A.; Casagli, N. Ground Subsidence Susceptibility (GSS) Mapping in Grosseto Plain (Tuscany, Italy) Based on Satellite InSAR Data Using Frequency Ratio and Fuzzy Logic. Remote Sens. 2019, 11, 2015. [CrossRef]

15. Kim, J.S.; Kim, D.J.; Kim, S.W.; Won, J.S.; Moon, W.M. Monitoring of urban land surface subsidence using PSInSAR. Geosci. J. 2007, 11, 59-73. [CrossRef]

16. Crosetto, M.; Monserrat, O.; Cuevas-González, M.; Devanthéry, N.; Crippa, B. Persistent Scatterer Interferometry: A review. ISPRS J. Photogramm. Remote Sens. 2016, 115, 78-89. [CrossRef]

17. Le, T.; Chang, C.P.; Nguyen, X.; Yhokha, A. TerraSAR-X Data for High-Precision Land Subsidence Monitoring: A Case Study in the Historical Centre of Hanoi, Vietnam. Remote Sens. 2016, 8, 338. [CrossRef]

18. Tran, V.A.; Tran, Q.C.; Vast, H.; Nguyen, D.A.; Vast, H.; Ho, T.M.D.; Tran, T.A.; Nguyen, N.H.; Luong, T.T.L. Application of PSInSAR method for determining of land subsidence in Hanoi city by Cosmo-Skymed imagery. In Proceedings of the International Conference on GeoInformatics for Spatial-Infrastructure Development in Earth and Allied Sciences, Hanoi, Vietnam, 12-15 November 2016.

19. Braun, A.; Hochschild, V.; Pham, G.T.; Nguyen, L.H.K.; Bachofer, F. Linking land subsidence to soil types within Hue city in Central Vietnam. J. Vietnam. Environ. 2020, 12. [CrossRef]

20. Hoa, P.; Giang, N.; Binh, N.; Hai, L.; Pham, T.D.; Hasanlou, M.; Tien Bui, D. Soil Salinity Mapping Using SAR Sentinel-1 Data and Advanced Machine Learning Algorithms: A Case Study at Ben Tre Province of the Mekong River Delta (Vietnam). Remote Sens. 2019, 11, 128. [CrossRef]

21. Ho Tong Minh, D.; Van Trung, L.; Toan, T. Mapping Ground Subsidence Phenomena in Ho Chi Minh City through the Radar Interferometry Technique Using ALOS PALSAR Data. Remote Sens. 2015, 7, 8543-8562. [CrossRef]

22. Erban, L.E.; Gorelick, S.M.; Zebker, H.A. Groundwater extraction, land subsidence, and sea-level rise in the Mekong Delta, Vietnam. Environ. Res. Lett. 2014, 9, 084010. [CrossRef]

23. General Statistics Office of Vietnam. Statistical Yearbook of Vietnam 2019: Population and Employment, 2019. Available online: https:/ / www.gso.gov.vn/en/data-and-statistics/2020/09/statistical-yearbook-2019/ (accessed on 15 August 2020) 
24. Tran Ngoc, T.D.; Perset, M.; Strady, E.; Phan, T.S.H.; Vachaud, G.; Quertamp, F.; Gratiot, N. Ho Chi Minh City Growing with Water-Related Challenges; Technical Report; United Nations Educational, Scientific, and Cultural Organization (UNESCO): Paris, France, 2016; ISBN 978-92-3-100161-1.

25. Sekkei, N. The Study on the Adjustment of the HCMC Master Plan Up to 2025; Technical Report; Urban Planning Institute (UPI): Ho Chi Minh City, Vietnam, 2007.

26. United Nations Department of Economic and Social Affairs (UN DESA). World Urbanization Prospects: The 2018 Revision; United Nations Publications: New York, NY, USA, 2019.

27. Angel, S.; Blei, A.; Lamson-Hall, P.; Galarza Sanchez, N.; Civco, D.; Lei, R.; Thom, K. Atlas of Urban Expansion-2016 Edition; Volume 1: Areas and Densitiies; NYU Urban Expansion Program at New York University, UN-Habitat, and the Lincoln Institute of Land Policy: Cambridge, MA, USA, 2016.

28. The Ho Chi Minh City Department of Planning and Architecture. Ho Chi Minh City Urban Planning Information, 2020. Available online: https://thongtinquyhoach.hochiminhcity.gov.vn/ (accessed on 21 July 2020).

29. Blate, G. The Greater Mekong and Climate Change: Biodiversity, Ecosystem Services and Development at Risk; World Wildlife Foundation: Bangkok, Thailand, 2009.

30. Downes, N.K.; Storch, H.; Schmidt, M.; Nguyen, T.C.V.; Dinh, L.C.; Tran, T.N.; Hoa, L.T. Understanding Ho Chi Minh City's Urban Structures for Urban Land-Use Monitoring and Risk-Adapted Land-Use Planning. In Sustainable Ho Chi Minh City: Climate Policies for Emerging Mega Cities; Katzschner, A., Waibel, M., Schwede, D., Katzschner, L., Schmidt, M., Storch, H., Eds.; Springer International Publishing: Cham, Switzerland, 2016; pp. 89-116._6. [CrossRef]

31. Minderhoud, P.S.J.; Coumou, L.; Erkens, G.; Middelkoop, H.; Stouthamer, E. Mekong delta much lower than previously assumed in sea-level rise impact assessments. Nat. Commun. 2019, 10, 3847. [CrossRef]

32. Dang, T.N.; Van, D.Q.; Kusaka, H.; Seposo, X.T.; Honda, Y. Green Space and Deaths Attributable to the Urban Heat Island Effect in Ho Chi Minh City. Am. J. Public Health 2018, 108, S137-S143. [CrossRef] [PubMed]

33. Nearing, M.; Pruski, F.; O’Neal, M. Expected climate change impacts on soil erosion rates: A review. J. Soil Water Conserv. 2004, 59, 43-50.

34. Ministry of Environment and Natural Resources (MoNRE); World Bank Vietnam; DANIDA. Vietnam Environment Monitor 2006: Water Quality in Viet Nam with a Focus on the Cau, Nhue-Day and Dong Nai River Basins; Technical Report; MoNRE: Hanoi, Vietnam, 2006.

35. Erban, L.E.; Gorelick, S.M.; Zebker, H.A.; Fendorf, S. Release of arsenic to deep groundwater in the Mekong Delta, Vietnam, linked to pumping-induced land subsidence. Proc. Natl. Acad. Sci. USA 2013, 110, 13751-13756. [CrossRef] [PubMed]

36. Minderhoud, P.S.J.; Erkens, G.; Pham, V.H.; Bui, V.T.; Erban, L.; Kooi, H.; Stouthamer, E. Impacts of 25 years of groundwater extraction on subsidence in the Mekong delta, Vietnam. Environ. Res. Lett. 2017, 12, 064006. [CrossRef]

37. People's Committee of Ho Chi Minh City. Issuing a Plan for Implementation of the First City's Meeting Decision on the Phase Depreciation Program 2016-2020; (Translated), 2016. Available online: http://tcvg. hochiminhcity.gov.vn/pages/7ctdp5.aspx (accessed on 25 July 2020).

38. People's Committee of Ho Chi Minh City. Issuing the Plan to Reduce Under-Land Water Disposal and Examination of Under-Land Water Exploitation Plan in Ho Chi Minh City by 2025 (Translated), 2018. Available online: http:/ / tcvg.hochiminhcity.gov.vn/pages/7ctdp6.aspx (accessed on 25 July 2020).

39. Zoccarato, C.; Minderhoud, P.S.J.; Teatini, P. The role of sedimentation and natural compaction in a prograding delta: Insights from the mega Mekong delta, Vietnam. Sci. Rep. 2018, 8, 11437. [CrossRef]

40. Trung, L.V.; Dinh, H.T.M. Monitoring Land Deformation Using Permanent Scatterer INSAR Techniques (case study: Ho Chi Minh City). In Proceedings of the 7th FIG Regional Conference: Spatial Data Serving People-Land Governance and the Environment-Building the Capacity, Hanoi, Vietnam, 19-22 October 2009.

41. Hu, J.; Li, Z.; Ding, X.; Zhu, J.; Zhang, L.; Sun, Q. Resolving three-dimensional surface displacements from InSAR measurements: A review. Earth-Sci. Rev. 2014, 133, 1-17. [CrossRef]

42. Fuhrmann, T.; Garthwaite, M.C. Resolving three-dimensional surface motion with InSAR: Constraints from multi-geometry data fusion. Remote Sens. 2019, 11, 241. [CrossRef]

43. Hooper, A.; Segall, P.; Zebker, H. Persistent scatterer interferometric synthetic aperture radar for crustal deformation analysis, with application to Volcán Alcedo, Galápagos. J. Geophys. Res. 2007, 112, B07407. [CrossRef] 
44. Lempert, R.; Kalra, N.; Peyraud, S.; Mao, Z.; Tan, S.B.; Cira, D.; Lotsch, A. Ensuring Robust Flood Risk Management in Ho Chi Minh City; Policy Research Working Papers; The World Bank: Washington, DC, USA, 2013. [CrossRef]

45. Vo, P.L. Urbanization and water management in Ho Chi Minh City, Vietnam-issues, challenges and perspectives. GeoJournal 2007, 70, 75-89. [CrossRef]

46. Copernicus. Sentinel-1 Data 2017 to 2019. Retrieved from ASF DAAC [8 Nov 2019], Processed by ESA. Available online: https: / / asf.alaska.edu/ (accessed on 14 October 2020).

47. Ferretti, A.; Prati, C.; Rocca, F. Nonlinear subsidence rate estimation using permanent scatterers in differential SAR interferometry. IEEE Trans. Geosci. Remote Sens. 2000, 38, 2202-2212. [CrossRef]

48. Delgado Blasco, J.; Foumelis, M.; Stewart, C.; Hooper, A. Measuring Urban Subsidence in the Rome Metropolitan Area (Italy) with Sentinel-1 SNAP-StaMPS Persistent Scatterer Interferometry. Remote Sens. 2019, 11, 129. [CrossRef]

49. Prats-Iraola, P.; Scheiber, R.; Marotti, L.; Wollstadt, S.; Reigber, A. TOPS Interferometry with TerraSAR-X. IEEE Trans. Geosci. Remote Sens. 2012, 50, 3179-3188. [CrossRef]

50. Walter, D.; Busch, W. Influences of DEM quality parameters on the topographic phase correction in DInSAR. In Proceedings of the 2012 IEEE International Geoscience and Remote Sensing Symposium, Munich, Germany, 22-27 July 2012; IEEE: Munich, Germany, 2012; pp. 3927-3930. [CrossRef]

51. Hooper, A.; Bekaert, D.; Spaans, K.; Arıkan, M. Recent advances in SAR interferometry time series analysis for measuring crustal deformation. Tectonophysics 2012, 514-517, 1-13. [CrossRef]

52. Chen, C.; Zebker, H. Phase unwrapping for large SAR interferograms: Statistical segmentation and generalized network models. IEEE Trans. Geosci. Remote Sens. 2002, 40, 1709-1719. [CrossRef]

53. Bekaert, D.; Walters, R.; Wright, T.; Hooper, A.; Parker, D. Statistical comparison of InSAR tropospheric correction techniques. Remote Sens. Environ. 2015, 170, 40-47. [CrossRef]

54. Yu, C.; Li, Z.; Penna, N.T.; Crippa, P. Generic Atmospheric Correction Model for Interferometric Synthetic Aperture Radar Observations. J. Geophys. Res. Solid Earth 2018, 123, 9202-9222. [CrossRef]

55. Cuong, T.Q.; Ho Tong Minh, D.; Van Trung, L.; Le Toan, T. Ground subsidence monitoring in Vietnam by multi-temporal InSAR technique. In Proceedings of the 2015 IEEE International Geoscience and Remote Sensing Symposium (IGARSS), Milan, Italy, 26-31 July 2015; IEEE: Milan, Italy, 2015; pp. 3540-3543. [CrossRef]

56. Tadono, T.; Ishida, H.; Oda, F.; Naito, S.; Minakawa, K.; Iwamoto, H. Precise Global DEM Generation by ALOS PRISM. In Proceedings of the ISPRS Annals of Photogrammetry, Remote Sensing and Spatial Information Sciences, Suzhou, China, 14-16 May 2014; Volume II-4, pp. 71-76. [CrossRef]

57. Santillan, J.R.; Makinano-Santillan, M. Vertical accuracy assessment of 30-M resolution alos, aster, and srtm global dems over northeastern mindanao, Philippines. In Proceedings of the ISPRS-International Archives of the Photogrammetry, Remote Sensing and Spatial Information Sciences, Prague, Czech Republic, 12-19 July 2016; Volume XLI-B4, pp. 149-156. [CrossRef]

58. Vernimmen, R.; Hooijer, A.; Pronk, M. New ICESat-2 Satellite LiDAR Data Allow First Global Lowland DTM Suitable for Accurate Coastal Flood Risk Assessment. Remote Sens. 2020, 12, 2827. [CrossRef]

59. Zhang, Y.; Wu, J.; Xue, Y.; Wang, Z.; Yao, Y.; Yan, X.; Wang, H. Land subsidence and uplift due to long-term groundwater extraction and artificial recharge in Shanghai, China. Hydrogeol. J. 2015, 23, 1851-1866. [CrossRef]

60. Wang, G.Y.; Zhu, J.Q.; Zhang, D.; Wu, J.Q.; Yu, J.; Gong, X.L.; Gou, F.G. Land subsidence and uplift related to groundwater extraction in Wuxi, China. Q. J. Eng. Geol. Hydrogeol. 2020, 53, 609-619. [CrossRef]

61. Dang, V.K.; Doubre, C.; Weber, C.; Gourmelen, N.; Masson, F. Recent land subsidence caused by the rapid urban development in the Hanoi region (Vietnam) using ALOS InSAR data. Nat. Hazards Earth Syst. Sci. 2014, 14, 657-674. [CrossRef]

62. Nguyen, Q.T. The Main Causes of Land Subsidence in Ho Chi Minh City. Procedia Eng. 2016, 142, $334-341$. [CrossRef]

63. Dang, A.T.N.; Kumar, L. Application of remote sensing and GIS-based hydrological modelling for flood risk analysis: A case study of District 8, Ho Chi Minh city, Vietnam. Geomat. Nat. Hazards Risk 2017, 8, 1792-1811. [CrossRef] 
64. Church, J.; Clark, P.; Cazenave, A.; Gregory, J.; Jevrejeva, S.; Levermann, A.; Merrifield, M.; Milne, G.; Nerem, R.; Nunn, P.; et al. Sea Level Change. In Climate Change 2013: The Physical Science Basis; Stocker, T.F.; Qin, D.; Plattner, G.-K.; Tignor, M.; Allen, S.K.; Boschung, J.; Nauels, A.; Xia, Y.; Bex, V.; Midgley, P.M., Eds.; Contribution of Working Group I to the Fifth, Assessment Report of the Intergovernmental Panel on Climate Change; Cambridge University Press: Cambridge, UK, 2013.

Publisher's Note: MDPI stays neutral with regard to jurisdictional claims in published maps and institutional affiliations.

(c) 2020 by the authors. Licensee MDPI, Basel, Switzerland. This article is an open access article distributed under the terms and conditions of the Creative Commons Attribution (CC BY) license (http://creativecommons.org/licenses/by/4.0/). 